\title{
"Times are changing ... and so must we" Integral Logistics and Services for the World-Scale Producer in Switzerland
}

\author{
Erich Habegger*, Georg Kirschbaum, and Ivan Vollenweider
}

\begin{abstract}
The chemical distribution business has traditionally consisted of a more or less one-way flow of information and products channeled through the distributor's organization. Changes in the industry require more integral service-oriented models to meet current needs. Distributors become both the supplier's and the customer's partner in the supply chain management, with an awareness of their partners' key objectives and strategies. The European chemical distribution market is highly fragmented. In order to be able to provide the required broad range of services and to run the business on a sustainable economic basis, the distribution operations must exceed a critical minimal size. Therefore a consolidation tends to shift towards larger distributors with broader services and product ranges. The competitive supplier in the chemical distribution business must provide a complete service. The following activities are viewed as essential elements of this integral service: Storage and materials handling, transportation, dispensing and refilling operations (if necessary in clean rooms under cGMP conditions), mixing and blending operations, tailor-made labeling, recovery and disposal service, quality control support, and last but not least experts advising the customer on chemical, technical, application, safety, logistical and commercial issues. Chemical distributors represent and serve important sectors of the chemical industry's value chain.
\end{abstract}

Keywords: Chemical distribution market · Logistics · Transportation · Warehousing

\section{Introduction}

In 1999 the chemical industry in Switzerland sold products valued at about CHF 87 billion, $39 \%$ of which went into the domestic market and represented $10 \%(68,000)$ of all Swiss jobs. The share of chemical specialties in the portfolio was $90 \%$, which, compared with international standards, is a very high figure. The product range is very wide and contains pharmaceuticals, diagnostics, fragrances, agrochemicals, cleaners, etc., adding up to about 30,000 different chemicals produced and commercialized in Switzerland [1].
${ }^{\star}$ Correspondence: Dr. E. Habegger

Schweizerhall Chemie AG

Elsässerstrasse 231

$\mathrm{CH}-4013$ Basel

Tel.: +41613268111

Fax: +41613268260

E-Mail: erich.habegger@schweizerhall.ch
A fragmented chemical distribution sector has contributed to an initial period of consolidation which is believed likely to continue as chemical producers and their customers shift towards larger distributors with broad product ranges and international or even global players.

The recent trend of outsourcing logistics services, which are viewed as non-core, is providing those chemical distributors who are able to realize substantial economies of scale and wide geographical coverage with significant opportunities. The European chemical distribution market, which is made up of some 1,500 companies, reported a turnover of $€ 22$ billion in 2001 with the top five chemical distribution companies representing $29.4 \%$ of the market. Univar and Brenntag, the top ranking players in the sector, accounted for $18.5 \%$ of the market. The type of product also impacts the level of service provided by the chemical distribution companies. Industrial chemicals account for approximately $80 \%$ of the volume and require a well-balanced logistics set-up that allows for efficient bulk-breaking and subsequent local fine distribution [2].

For logistics, chemical companies still tend to use several different suppliers, resulting in a severely fragmented and sub- optimal transportation system. With the current emphasis on further cost optimization, there is a continuous shift towards improving the supply chain management. The most powerful distributors, with substantial and complete physical networks as well as effective information technology solutions, will benefit by partnering suppliers and customers. Approximately 31\% of the European distribution market is outsourced, compared with $41 \%$ in the US. This clearly demonstrates that the European market still has strong growth potential.

Additional opportunities to broaden the range of services into new businesses can be identified in areas such as blending, mixing, or recapping operations. Activities like the management of storage facilities on behalf of the customer are increasingly gaining importance. Reverse logistics for spent processing chemicals, such as chlorinated or hydrocarbon solvents, is also a segment of growing significance [2].

\section{Chemical Distribution Market - "times are changing"}

The chemical distribution business has traditionally consisted of a more or less 


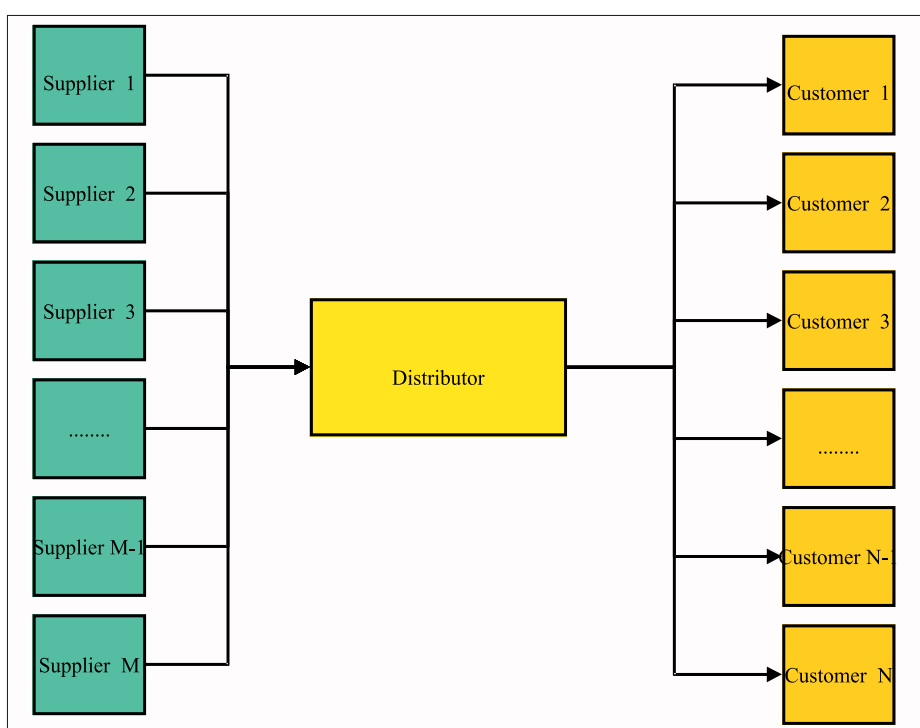

Fig. 1. Distributors in the past - one-way flow of information and products between suppliers and customers

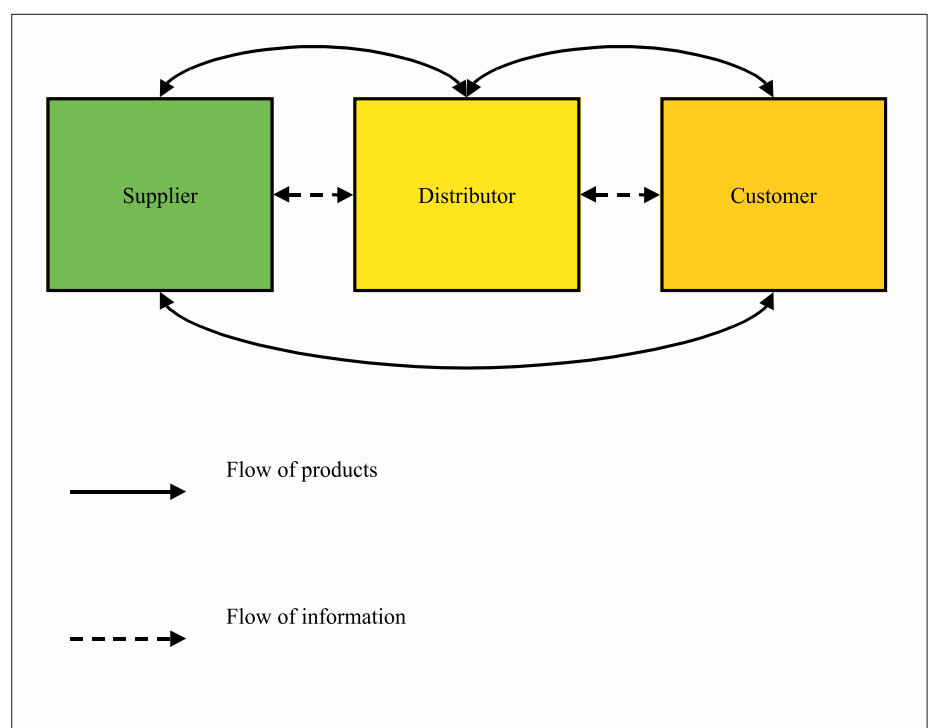

Fig. 2. Distributors now - two-way flow of information and products between suppliers and customers one-way flow of information and products channeled through the distributor's organization (Fig. 1).

Changes in the industry require more complex models to meet current needs. Keywords in this context are responsiveness and flexibility based on a better understanding of the customers' needs: service level, range of demand, response time, product variety, innovation and low price.

One of the most important tasks of the distributor is to provide quality products in full compliance with all the regulations and to use strictly approved suppliers. This service includes the search for suitable sources, evaluation and approval of products and suppliers. Necessary information and documentation consist of agreed product specifications and certificates of analysis for each delivery, if required. For specific applications and certain market sectors additional documentation such as kosher, BSE certificates, GMO labeling, ICH-guidelines, etc. are obligatory. The requirement for chemical purity and cleanliness of plant and packaged products is self-evident.

Strategic locations, warehouse capacities and an effective logistics organization enhance delivery precision, short lead times and backup stocks.

Transportation capacities by water, road or rail respond to different customers' requirements. Distribution services may further include the provision of direct shipments from the manufacturer to the customer. Alternatives might include consignment stocks and network-controlled bulk tanks in the customer's plants, guaranteeing automatic refills when needed.

Ideally, the distributor is in a position to give customers effective technical support. Thorough product and application expertise may generate new innovative solutions. Tailor-made services or formulations can be created by close cooperation between the customer, the manufacturer and the distributor. Even joint product developments are possible. New customer needs due to any changes and developments in the market have to be monitored closely.

The distributor must be engaged in ongoing communication between the suppliers and the customers at all relevant levels. Besides the daily routine contacts covering offers and orders, the distributor has to track carefully any deviations and potential problems. Efficient responsiveness to product claims and challenges is an absolute must.

Another important challenge facing the distributor is the optimization of sourcing in order to guarantee supply security and acceptable pricing conditions. Based on the established strategic suppliers and the permanent search for alternative sources on a global basis, the distributor is aiming for a continuous improvement of his services for the benefit of the customer, and ultimately also for his own benefit.

Naturally, the importance of the abovementioned factors varies, depending on the needs of the different industrial sectors. While pharmaceuticals and cosmetics manufacturers for example rely on complete and thorough product documentation, other sectors, like the paint industry, are more price-driven. However, nearly all customers require short lead times and just-in-time deliveries. The function of the distributor has therefore become more complex and service-oriented.

Distributors become both the supplier's and the customer's partner in the supply chain management, with an awareness of their partners' key objectives and strategies.

The lines of communication and the flow of materials must also be two-way and the process itself must be iterative in order to guarantee continuous improvement (Fig. 2).

\section{Operations}

\subsection{General Aspects}

In order to be able to provide the required broad range of services and to run the business on a sustainable economic basis, the distribution operations must exceed a critical minimum size. Solvents, acids, bases and other chemicals which are commonly used in large quantities have to be made available to the customer in sufficient quantities at all times. Also, less commonly used chemicals and specialties are shipped to the customer at increasingly short notice. A distribution operation can therefore only be run efficiently with an adequate storage and transportation capacity. Experience shows that a range in the order of 10,000 products, or even more, has to be maintained to be a really valuable competitive partner and to satisfy the needs of industrial customers. In addition, many products are requested in a variety of packaging units. For instance, a solvent is used in the laboratory on a liter basis, in the pilot plant on a drum basis (200 1) and finally in production on a multi-ton basis.

A practical overview of a state-of-theart distribution operation that meets the needs and expectations of the Swiss market is in the Table, based on the experience of Schweizerhall Chemie AG, Basel.

\subsection{Storage and Materials Handling}

The materials handling must generally be driven by the following considerations:

- To comply with all pertinent requirements regarding safety and quality (including cGMP aspects, if applicable); 
Table. Key figures for Schweizerhall Chemie AG, Basel

$\begin{array}{ll}\text { Founded } & 1890 \\ \text { Sales (2003) } & 215 \text { Mio CHF } \\ \text { Number of employees } & 234 \\ \text { Business locations } & \text { Basel, Avenches, Flawil, Lohn } \\ & \\ \text { Storage capacities } & 30,000 \mathrm{~m}^{2} \\ \text { Warehouse } & 7000 \text { pallets } \\ \text { High bay warehouse } & 10,000 \text { drums } \\ \text { Compact high bay warehouse } & 14,000 \mathrm{~m}^{3} \\ \text { Tank farm } & 29 \text { special vehicles fleet } \\ \end{array}$

- To optimize direct labor costs versus investment costs by the mechanization and automation of the vital materials handling operations.

The fact that substances which are chemically incompatible should not be stored together is one of the driving factors for a safe storage operation. Typically, different fire compartments have to be made available for the following substance categories [3]:

- Substances igniting or generating flammable gases in contact with water

- Substances reacting violently and generating corrosive/toxic gases in contact with water

- Oxidizing substances

- Organic peroxides

- Explosive substances

- Compressed or liquefied gases

- Substances reacting spontaneously

- Quarantine products (e.g. very recently shrink-wrapped goods)

The above-cited categories are not necessarily complete and might have to be extended according to the specific requirements of the substances involved.

For liquid bulk products an overall tank farm capacity of over $10,000 \mathrm{~m}^{3}$, consisting of tanks with a sufficiently broad volume distribution, is a must. Ubiquitously used solvents, like methanol, toluene, etc., require storage tanks with a capacity exceeding $1000 \mathrm{~m}^{3}$ to guarantee reliability of supply and to be competitive.

A high-bay warehousing capacity of approximately 7000 pallet spaces is used to store the base load of chemicals and specialties. In addition, a unique compact high-bay warehouse has recently been brought into service (Fig. 3). The facility was primarily put on stream to enhance the efficient handling of high quality, flammable solvents in drums. Up to 2500 pallets containing 10,000 drums (200 l) can be stored in the compact high-bay warehouse.
The facility also includes 15 stainless steel storage tanks of $60 \mathrm{~m}^{3}$ capacity each, and a fully automated multi-product drum filling station (Fig. 4). The entire installation is in full compliance with the stringent cGMP standards.

Last but not least, a general storage area for various substances of over $30,000 \mathrm{~m}^{2}$ is necessary to enable the integral basic service expected by the Swiss customer base. This storage area of course also has to be segregated in accordance with the chemical nature of the substances involved, as discussed above.

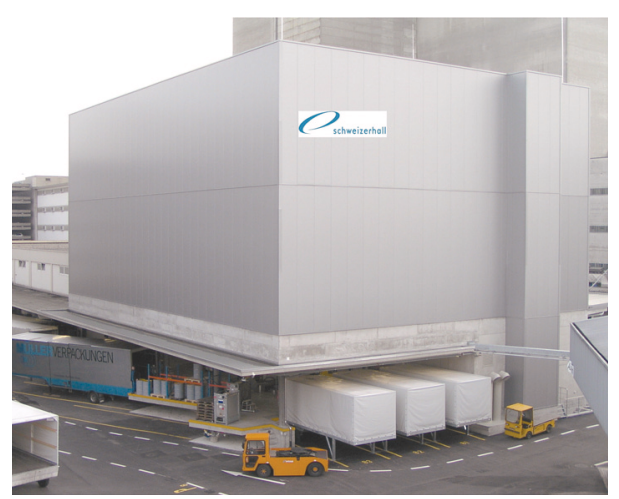

Fig. 3. Compact high-bay warehouse for flammable solvents

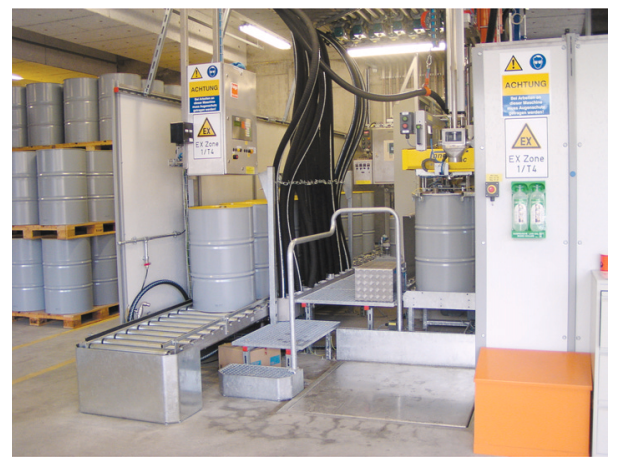

Fig. 4. Fully automated multi-product drum filling station

\subsection{Transportation}

The most efficient means of transportation has to be made available, always taking into consideration the nature and quantity of the substance to be hauled.

- Water transportation: Large volumes of bulk chemicals and solvents are carried by ship on the river Rhine to Basel. To make use of this extremely efficient transportation method, tanks with a capacity of several thousand cubic meters have to be provided.

- Road transportation: The base load of liquid bulk chemicals, solvents and solid products is carried by a companyowned fleet of special trucks (Fig. 5).

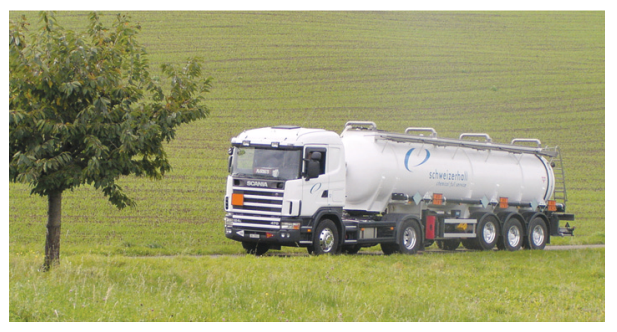

Fig. 5. Special truck for chemicals

The maximum capacity is 28 to per truck and a number of trucks are even equipped with subdivided chambers of different sizes $\left(2.5 \mathrm{~m}^{3}\right.$ up to $\left.7 \mathrm{~m}^{3}\right)$ to further increase the flexibility of this service. The appropriate choice of construction materials for the bulk tanks enables acidic and basic substances as well as neutral products like solvents to be transported. The relevance of operating a company-owned fleet with welltrained personnel is becoming more and more a strategic success factor for a chemical distributor, given the increasing importance of safety and reliability issues. Peak demands for transportation capacity have to be covered by third parties.

- Rail transportation: Distributor-owned as well as rented rail cars are currently being utilized. Ongoing developments indicate that there is an increasing trend towards the use of rented rail cars.

Another key parameter of transportation efficiency is, of course, the number of supply points. To cover the Swiss market it can be shown that two supply points are adequate to guarantee short lead times and competitive pricing (e.g. Basel: to service the central and eastern part of Switzerland; Avenches: to service the western part of Switzerland).

\subsection{Recovery and Disposal Service}

The disposal of chemical waste, and in certain cases the recovery of spent solvents as well, are typically not part of the customer's core business. 
Therefore

- Pick-up service for chemical waste and spent solvents

- Professional disposal of chemical waste

- Recovery of solvents

are viewed as an ideal and valuable addition to the existing service line.

\subsection{Other Services}

Additional services which are considered to be part of an integral service of a chemical distributor are:

- Refilling and repackaging operations

- Tailor-made labeling

- Mixing and blending operations

- Dispensing and refilling operations under cGMP conditions in clean rooms

- Quality control services

- Experts who can advise the customer regarding chemical, technical, safety, logistical and commercial issues

\subsection{Information Technology}

This chemical distribution business is characterized by an extremely high number of products $(>10,000)$ coupled with a large number of customers and numerous customer-specific requirements. On an average working day, well over 1000 individual orders have to be processed by the system. Planning of the available resources is therefore an extremely demanding task. The goal must be to achieve optimum capacity utilization in terms of storage and transportation resources. However, conflicting interests within the logistics operations have to be carefully balanced. Due to the inherent complexity of this situation, a state-of-theart information technology support, like a fully integrated SAP environment, is an absolute necessity.

\subsection{Quality}

In order to assure all the relevant quality-related issues, the organization charts of the company must reflect this fact clearly.

The ISO management system standards, which are implemented and recognized worldwide, play an important role. Customers specifically expect a distributor to be certified according to ISO 9001 and ISO 14001.

Depending on the application of the products involved, various standards are to be adhered to: for instance food-grade chemicals are governed by the Food Chemicals Codex.

Substances used for pharmaceuticals are to be handled according to the guidance for industry ICH Q7A. Other important guidelines in this context are the standards published in the relevant national pharmacopeias, e.g. United States Pharmacopoeia, European Pharmacopoeia, Pharmacopoeia Helvetica.

Critical tasks which are within the responsibility of the quality department are to be controlled exclusively by designated personnel: e.g. releasing and rejecting products, approving specifications, ensuring that critical deviations are investigated thoroughly, supervising qualification and validation processes, making sure that quality audits are performed etc.

\subsection{Safety and Ecology}

In today's legal and economic environment, it is absolutely vital to adhere to international standards of safety and ecology. For that specific purpose, membership of organizations like the International Organization for Standardization's ISO management system, the Responsible Care ${ }^{\circledR}$ program and the European Union Eco-Management and Audit Scheme (EMAS) is also a must for integrated distributors.

Modern warehouses and tank farms for chemicals are rather complex installations and need to be equipped with numerous safety features to fulfill the legal requirements (fire and smoke detectors, sprinkler systems, fire-water retention capabilities).

A comprehensive training program for all employees is another essential building block to secure adequate safety as well as quality standards. The program has to involve the entire workforce in every aspect of the operations and has to be documented.

\section{Conclusion}

Chemical distributors represent and serve important sectors of the chemical industry's value chain.

From the manufacturer's point of view: "Distributors should not only be our commercial arm serving the end customer, but should also be a partner offering new, inno- vative services which increase profitability for the producer - such as stock management, formulation, packing and drumming, optimizing transportation models, and even running operations in our plants" [4].

Given the

- highly fragmented nature of the chemical distribution sector;

- reduced number of major companies due to mergers and acquisitions in the chemical industry;

- and the increased effort to achieve economies of scale by chemical distributors and major companies,

a further consolidation in the chemical distribution sector appears likely.

Only a limited number of companies provide complete supply chain management services. This is clearly an area where companies will be able to differentiate themselves, i.e. improve margins and overall profitability [2]. It is necessary to streamline these services on an ongoing basis. Successful optimization processes will be based on precise communication between both partners' structural elements like logistics, quality control, HSE, management, etc. This process must also include the implementation of an innovative contribution from the individuals involved, this development being driven by a close and strategic cooperation between the customer and the distributor in line with the long-term objectives of both sides.

Received: December 13, 2004

[1] H.-J. Hansen, 'Chemische Industrie', in 'Historisches Lexikon der Schweiz' (HLS electronic publication), version of 19.12.2003.

[2] KPMG, 'Snapshot: European chemical distributors sector', February 2003, No. 204-255.

[3] Expertenkommission für Sicherheit in der chemischen Industrie, ESCIS-Bulletin No. 6, 'Warehouses for Chemicals', Basel, May 1999.

[4] C. Jourquin, 'Solvay's Chemicals', Keynote Address, Diamond Awards Dinner of the British Chemical Distributors and Traders Association, February 2002. 